\title{
Indentation Mechanism in Rotary Hammer Forging Process: Analytical and Numerical Approach
}

\author{
Saud F. E. M. D. Alazemi, Irfan Hilmy and Erry Y. T. Adesta
}

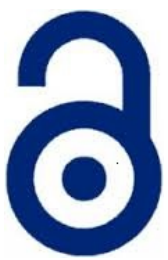

Received: 01 September 2018

Accepted: 13 September 2018

Published: 01 December 2018

Publisher: Deer Hill Publications

(c) 2018 The Author(s)

Creative Commons: CC BY 4.0

\begin{abstract}
Rotary hammer forging process is getting popular since it has many advantages comparing to the conventional forging process. The mechanism of the movement in term of orbital motion of the conical upper die become concern of this research. This article present the three stages of the modelling of the rotary hammer forging. The first stage is the development of the orbital motion of the conical upper die. Three-dimensional CAD model of the conical upper die was developed to determine the orbital motion as a function of the four parameters: Nutation, Precession, Spin and Rocking-Die mechanism. A reasonably accurate design of the conical upper die and the workpiece had been developed based on motion because of interaction of conical upper die and upper part of workpiece geometries. The behaviour of orbital motion with any active combination of those four parameters was observed. The second stage was the development of the conical upper die with the specific feature in order to generate a product with an unsymmetrical shape of upper part of the product. The sequence and mechanism of the formation of the upper part of product were generated. The third stage was the analysis of the stress strain state during the formation of the upper part of the workpiece. An elastic-plastic, dynamic analysis of 3D rotary hammer forging mechanism with the concern at the workpiece and their interaction with a model of dies have been performed. Verification of the indentation mechanism of the rotary hammer forging had been done by validating the result with the existing experimental results.
\end{abstract}

Keywords: Forging, Rotary hammer forging, Indentation mechanism, Conical upper die, Orbital motion

\section{INTRODUCTION}

Rotary Hammer Forging is one type of forging process which is also called as Wobble Die Forging. Parts that have circular feature such as bearing housing, gears, chain sprocket, coupling and clutch hubs are produced by this process. Those parts can be found mostly in the automotive industry. It was realized that nearly $85 \%$ of all forged parts have a circular shape. In the era of extreme global competition, improvement toward an efficient process will enhance the forging quality and lead to the cost reduction and greater productivity. However, designing new forging process for a more complicated shape of an object is challenging. In addition, to be competitive, the processes are to be faster and accurate method on designing forging mechanism as well as the dies $[1,2,3]$. In this quite competitive era in the business, product life cycle should be shorter to be competitive. As such a faster design for metal forging process is necessary. Hence, the research questions are:

1. Is there any standard guideline to design the conical upper die of a rotary hammer forging?

2. How to generate the motion of conical upper die based on a set of parameter?

3. How to select suitable workpiece material for dies in the rotary hammer forging?

4. Which friction model is suitable in modelling interaction between workpiece and upper conical and lower die?

The objective of this research is to develop a new method as a framework to design forging process as well as die design in a rotary hammer forging. The research objective can be broken-down into three specific objectives which are as follows:

S. E. M. F. Alazemi ${ }^{1} \otimes$, I. Hilmy ${ }^{2}$ and E. Y. T. Adesta ${ }^{3}$

Department of Manufacturing and Materials Engineering

International Islamic University Malaysia

PO Box 10, 50728 Kuala Lumpur, Malaysia

'E-mail: good-lucj78@hotmail.com

2E-mail: ihilmy@iium.edu.my

${ }^{3}$ E-mail: eadesta@iium.edu.my 
1. To develop the analytical analysis on orbital motion of the conical upper die of a rotary hammer forging process in order to identify the behaviour under different configuration of forging parameters,

2. To design the conical upper die with a specific feature and specific forging configuration, and

3. To develop a numerical stress analysis based on finite element model of the indentation process of the conical upper die to the upper region of the workpiece.

\subsection{Research Methodology and Hypothesis}

The first stage of the research is the development of the analytical model. At this stage, an integration of Solidworks with the add-on Motion feature and Matlab script has been utilized. The CAD (Computer Aided Design) model of the conical upper die as well as the workpiece has been developed. One point of interest has been identified and marked. Using Euler law of motion, the orbital motion equation has been derived analytically involving parameters of orbital motion: Nutation, Precession, Spin and the Rocking-Die mechanism. The second stage is the development of the additional feature at the upper conical die in order to generate workpiece with more intricate shape. The model was developed using Solidworks software. The developed model refers to the existing upper conical die shape. The scenario of the indentation process by combining the orbital motion at different setting of parameters of the upper conical die developed in the previous stage has been generated. The third stage is the stress analysis of the indentation process. The CAD model of the interaction of upper conical die and the workpiece was transferred to the AFDEX environment in order to perform a numerical, finite element based analysis of the rotary forging process. The research hypotheses on guidelines to the development of analytical and numerical model of the rotary hammer forging are as follows:

1. There is no unique way for the formation of profile indented to the upper part of workpiece. Different combination of the hammer forging parameters may offer alternate solutions.

2. Friction condition at the interfacial contact between the conical upper die and the workpiece will affect the process of the indentation.

3. Assumption of the conical upper dies as a rigid body object is reasonable

This study will contribute to the research and development in the forging industry sector. Shortening the PLC (Product Life (ycle) of a forging product becomes a compulsory requirement in the era of high and critical competition in any sectors especially in the manufacturing field. The proposed method my speed up the design stage in a relatively significant amount of time.

\section{LITERATURE REVIEW}

Based on report from the Association of Forging Industry [4], they record the increase of the forging product with the increase around $25 \%$ every year. The leading industry still the automotive sector with around $30 \%$ of total forging product have been fabricated. Forging processes are widely utilized mostly in the automotive and aircraft manufacturing company. More than 200 forged parts could be identified in a typical large car such as truck. The parts suffer large plastic deformation due to sudden impact load or a slow pressing load. Figure 2.1 shows some of the products fabricated using forging process. In the aerospace industries, around 400 forged part for structural components only and another 200 for the engine component. Apart from those to fields, other industries such as oil and gas sector, food processor, agricultural and electronics also used many forged part components.

\subsection{Classification of Forging Processes}

Forging process can be grouped into two major categories: open die forging and closed die forging. Open die forging was the first and can be considered ancient method of forging. Blacksmith was one of the oldest technique of the open die forging. Fabricating of the horseshoe, dagger, sword etc. utilize this type of forging. The power at that time only utilized human power. Therefore, the product can be considered small. Open die forging can be characterized by having an open space between dies and workpiece since no sidewall block the flow of the material during its process [5]. This condition will allow the material of workpiece to flow in the free space. Figure 1 shows the very basic of forging configuration: open die forging. Because of this configuration, the benefit of the open die forging is it can forge the large size of workpiece. Workpiece with weight can reach up to 100 tons can be forged with this open die configuration.

However, in case of close dies, the shape of the die is negative of the product. If the forging is performed, the workpiece will flow and occupy the negative shape space. This type of forging will produce a quite complex final product with tighter tolerance comparing to the open die forging. Nowadays, this type of forging process plays a dominant role in the forging industry. Figure 2 shows the schematic of the closed die forging. Based on the working temperature, forging can be grouped as cold forging and hot forging. It called cold forging if the process is performed at a room temperature. Lubricant is necessary since during cold temperature process, the friction play a significant role to the process. The result of cold forging is usually a finished product with a precise result. The disadvantage is the material does not become soft since no change in the grain structure. 


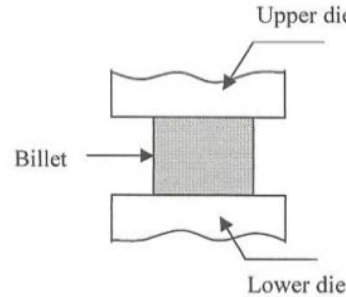

(a)

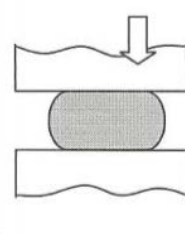

(b)

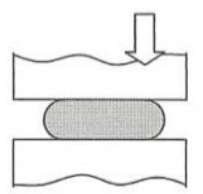

(c)

Figure 1: Open die forging (a) Initial condition, (b) and (c) Forging process [5]

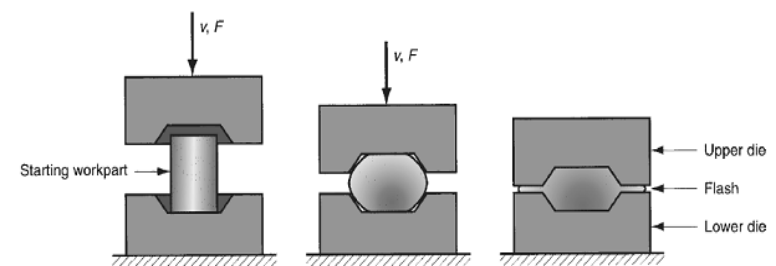

Figure 2: Closed die or impression die-forging from starting point until finish [5]

Table 1: Temperature range for various process [5]

\begin{tabular}{cc}
\hline Process & Ratio of processing temperature and meting point $\left(\mathrm{T}_{\mathrm{p}} / \mathrm{T}_{\mathrm{m}}\right)$ \\
\hline Cold working & $<0.3$ \\
Warm working & $0.3-0.5$ \\
Hot working & $>0.5$ \\
\hline
\end{tabular}

Meanwhile, hot forging is performed above the softening temperature where the strain hardening is released during this stage the grain transform from a uniaxial shape become spherical shape. This condition will make the material flow easier and the forging force become lower. The workpiece usually large and bulk in shape and this hot forging process usually for the semi-finished product that need to be processed further. The disadvantage of this process is the oxidation at the surface during cooling process. This process is required to be processed in a faster way to avoid an excessive oxidation. As a guideline, for any metal workpiece, the range of the working temperature is shown in the Table 1. The range is displayed as a ratio over the melting temperature $T_{m}$.

In term of the type of power that pushes the forged material, there are two main group of forging machine: hammer or drop forging and press forging. Hammer forging work by hammering the workpiece with an instant impact. One of the method is utilizing the gravity hence the name is drop forging. The load is so sudden which act as an impact load. This process consequently is became faster but with the disadvantage that this mechanism is only applicable for a relatively smaller workpiece due to the limitation in the forging force. Press forging in the other side is using hydraulic press mechanism. The process is slower than hammer forging but in term of power capability multiple times higher than hammering. It can forge a large and bulk workpiece. In conclusion, depend on the requirement, both have advantages and disadvantages. For a demand of a large quantity product, time is very crucial. Only hammering can fulfil the criteria of an economically process.

\subsection{Characteristic of Rotary Forging}

Rotary forging was originated in Japan. Japan has been extensively developed research about rotary forging in almost every aspect. They investigated the performance of the machine, characteristic of stress strain behaviour, the accuracy of the forging process [6], the behaviour of the surface interaction between dies and workpiece. The research was backed up by the private sector as well as the support from the government. As the leader, Japan utilize this forging method in almost every sector of metal industry and give a significant contribution to their economy.

Cold rotary forging can be defined as an advanced and very complex forging technique involving a plastic deformation occurred locally. It has gain more popularity to produce many application in multi sector of industry covering machining equipment, automotive, electrical part and other hardware accessories. It has advantages including very low level of vibration as well as noise, adequate roughness and surface tolerance and relatively low cost and energy requirement. The coverage of the products or components that can be fabricated using rotary forging including flange, hub, cam, gear as well as the flat shape and thin disks. The shape of those parts can be grouped as an axisymmetric part. Rotary forging with normal orbital motion of die is suitable to forge them. If complex and 
axisymmetric component need to be fabricated, then the second type of rotary forging which is the rocking-die motion is applicable. The example of the products is bevel gear, differential gear and T-flanges.

Rotary forging is more suitable for the specimen, which have a high value of diameter over thickness ratio [7]. The reason is that workpiece with the large flange dimension more suitable to suffer rotary forging load. Only smaller axial force is needed if the high ratio of diameter over thickness is fulfilled. Another positive impact in the minimal quantity of friction occurs. This is because the shorter contact time between material or workpiece and their dies. The deformation is $30 \%$ more than the common forging process.

\subsection{Mechanism of Rotary Forging}

Figure 3 shows the mechanism of rotary forging machine. It has lower dies, which rotates continuously, and an upper dies with a conical shape that also rotates with a small inclination angle during its process. At particular time only small part of the workpiece receive the pressing load. The mechanism is called cyclic local pressure or compression. It is contrast with the common forging process which the workpiece received instant blow at the contact surface. Therefore, using this method, the force required to perform the forging process is lower than the common forging process. In the rotary forging process, the upper die oscillate rotating the vertical axis of the machine at a constant speed. At the same time, the workpiece is also being pushed by lower die upward direction. This mechanism is repeated simultaneously until it makes a result a perfect plastic deformation in an axisymmetric manner.

The numbered component is called Part. For example, Part 1 and Part 2 refer to the component number 1 and 2 respectively. Part 1 is the upper holder, which has a conical shape geometry that will contact directly with the workpiece. Part 1 is supported by Part 2, which has hemispherical head. It will allow Part 1 to move in a rocker-die mechanism. Part 23 is the main motor, which give power to all movement mechanism. The Part 3 is an upper plate, which act to secure the placement of Part 2. Part 25 is the Gearbox system that connected to the motor via the coupling system as indicated as Part 24. Part 25 reduces the output angular speed of the motor. Part 25 also act as axis changer that convert the horizontal axis of rotation become a vertical axis of rotation.

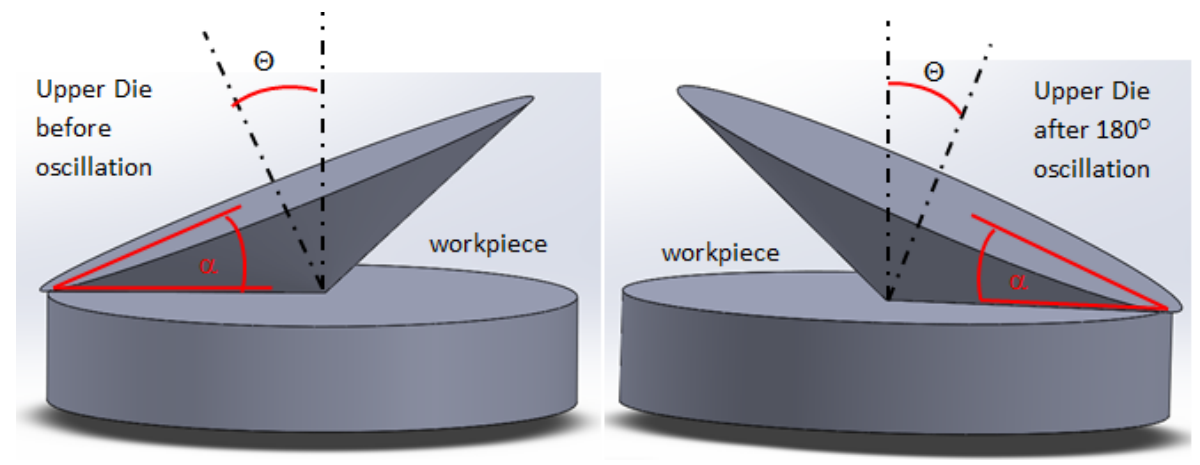

Figure 3: Concept of Rotary Forging

\subsection{Orbital Motion in Rotary Forging}

Development of the orbital motion of the conical upper die requires four independent parameters: Nutation (N) angle or rotation, Precession (P) angle or rotation, Spin (S) angle or rotation and the rocking die mechanism in $-\mathrm{Z}$ direction. Figure 4 shows the angle and axis conventions. It is a rotation along $x$-axis. All the existing rotary forging machines use one or some of the combination of N, P and S parameters. It can be seen that not all of the machines utilized all three angle of rotations parameters [8].

The difference between rotary press and hammer forging is in the speed of loading or indentation. Press forging is slower than hammer forging. In rotary hammer forging, the process of the die approaching the workpiece is in order of millisecond. The advantage of this rapid process is the process reduces the heat loss of the surface. The benefit is the improvement of the mechanical properties of the workpiece.

\subsection{Benefit of Forging Simulation}

The benefit of the Finite Element Modelling in Metal forming in general and specifically forging are as follows [9]. (1) The behaviour of the workpiece due to the heat treatment process could be predicted, (2) The stress-strain state during the forging process can be obtained, (3) The occurrence of failure in term of location as well as magnitude can be anticipated, (4) The die can be designed to include the wear and their respective lifetime in the considerations, (5) Reduce or even eliminate the trial and error in the product life cycle. 


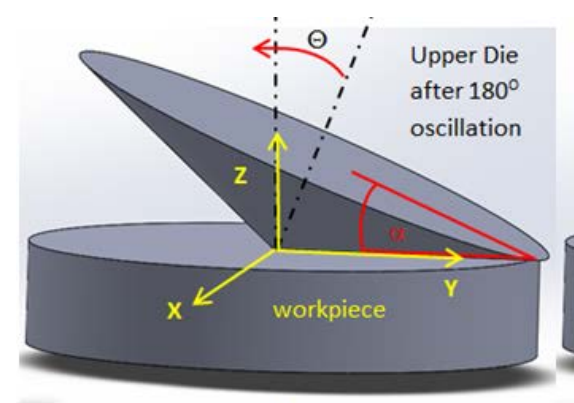

(a)

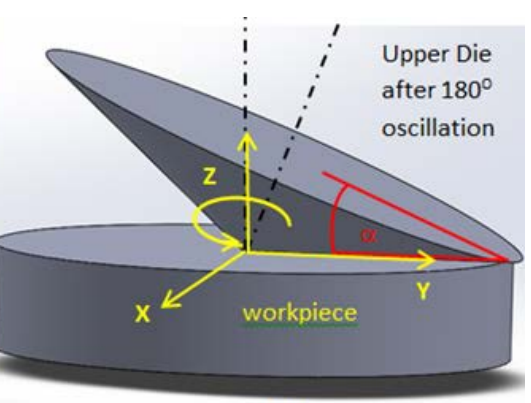

(b)

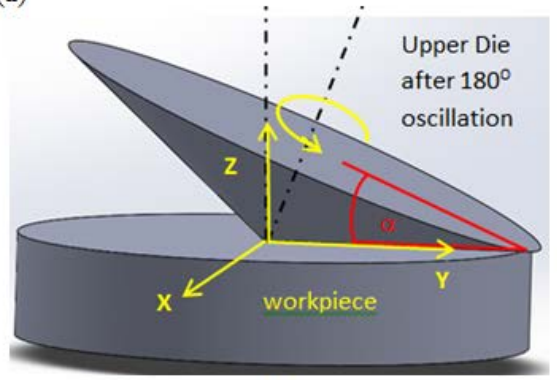

(c)

Figure 4: Three angular movements: (a) Nutation, (b) Precession and (c) Spin

In the forging field, it is common that development of the product involving simulation application. There are two types of the finite element based software available in the market. The commercial software and the specific tailor made software that have been developed specifically for the needs of the particular company. Simulation can be divided into two activities. Simulation of the workpiece and the dies. For each type of analysis, sometime the assumptions have been made whether to treat the dies as a rigid body or non-rigid body [10]. If the main concern is on the workpiece, the dies are considered rigid. Using this way, computational time can be reduced quite significant. Die configuration is grouped into two possible rigid and elastic. If die is considered as a rigid body, then no analysis is given to the die. In this case, die is not become a concern because for example the workpiece is relatively soft. If the workpiece is from a softer family of metal, then die deformation can be considered too small or not significant. The rest of the combinations treat the die material as an elastic body. Assumption has been made that the flow stress is an independent strain rate. For strain rate dependent, the flow stress curve will vary as function of the working temperature or the different speed of strain. Forging simulation getting popular due to some benefit. Three domain in the forging development consist of (1) Cost down, (2) Technological improvement and (3) Reduced lead times for development. Using finite element, various ideas can be explored through different model and design.

\section{FINITE ELEMENT MODELING IN AFDEX}

Development a simulation of metal forming in AFDEX is grouped into two categories. The first one is the modelling of the behaviour of the workpiece during their forming sequence. In analysis, focus is on the workpiece and usually it is a coupled analysis between flow analysis of workpiece and heat transfer analysis of workpiece. The coupled analysis also can be between the die structural analysis and the workpiece. The input and output parameters cover: (1) heat generation, (2) flow stress change, (3) mechanical load, (4) die geometry change, (5) heat transfer and (6) thermal load. AFDEX separate the analysis in the sub module. The separation of module is one way to reduce or optimize the resources in term of memory and disk space. Only the requested modules will be loaded to the memory. Once particular module has done with their work, they will be immediately unloaded from the memory. AFDEX provide basic geometry modelling feature such as importing the primitive shapes. Basic geometry such as cube, cylinder and hollow cylinder and sphere are available to be used as the basic shape.

\subsection{Meshing Technique}

Meshing is one important factor in the finite element analysis. It is a method how a continuum workpiece is being discretized into small elements. A real product can be modelled as one dimensional (1D), two-dimensional (2D) or three-dimensional (3D) element. The choice to determine the level of density of the meshing depends of some issues. In term of hardware requirement to be used as the computing machine, finer the mesh of the structure, the heavier load of the computing machine will be. Sometime, the refinement of the element size into half of the original, the computing time will increase exponentially. Enlarging the size of the meshing, the computing time can be reduced significantly. The disadvantages of a coarse meshing are missing some results at some locations and the geometry of the product is less accurate. Some intricate shape needs extra attention by giving a finer meshing. Narrow gap or sharp object requires a finer mesh. Otherwise, some important and significant gradient of the result might be missing. To compromise between coarse and fine element meshing, the localized fine meshing is the solution. Instead of 
making a homogeneous meshing, fine meshing is applied only at particular location or point of interest. AFDEX provide the feature for user to do localized meshing. Some techniques are available based on the shape of the enclosed region.

\subsection{AFDEX Material Library}

AFDEX provide a large collection of the material library with the properties detail. One main important curve is the material flow stress. Figure 5 shows the example of flow stress of a SCM440 Alloy Steel. Since this material is a strain rate dependent, the flow stresses are different at different level of working temperature. It can be seen that the higher working temperature, the lower flow stress occurred since the material getting softer. Thus, it is easier to pull the material at the higher level of working temperature. The flow stress also can be generated by choosing the suitable flow stress model as shown in the Table 4.3. Started from the least complex flow stress equation to the relatively complex flow stress equation which incorporating the damage parameters.

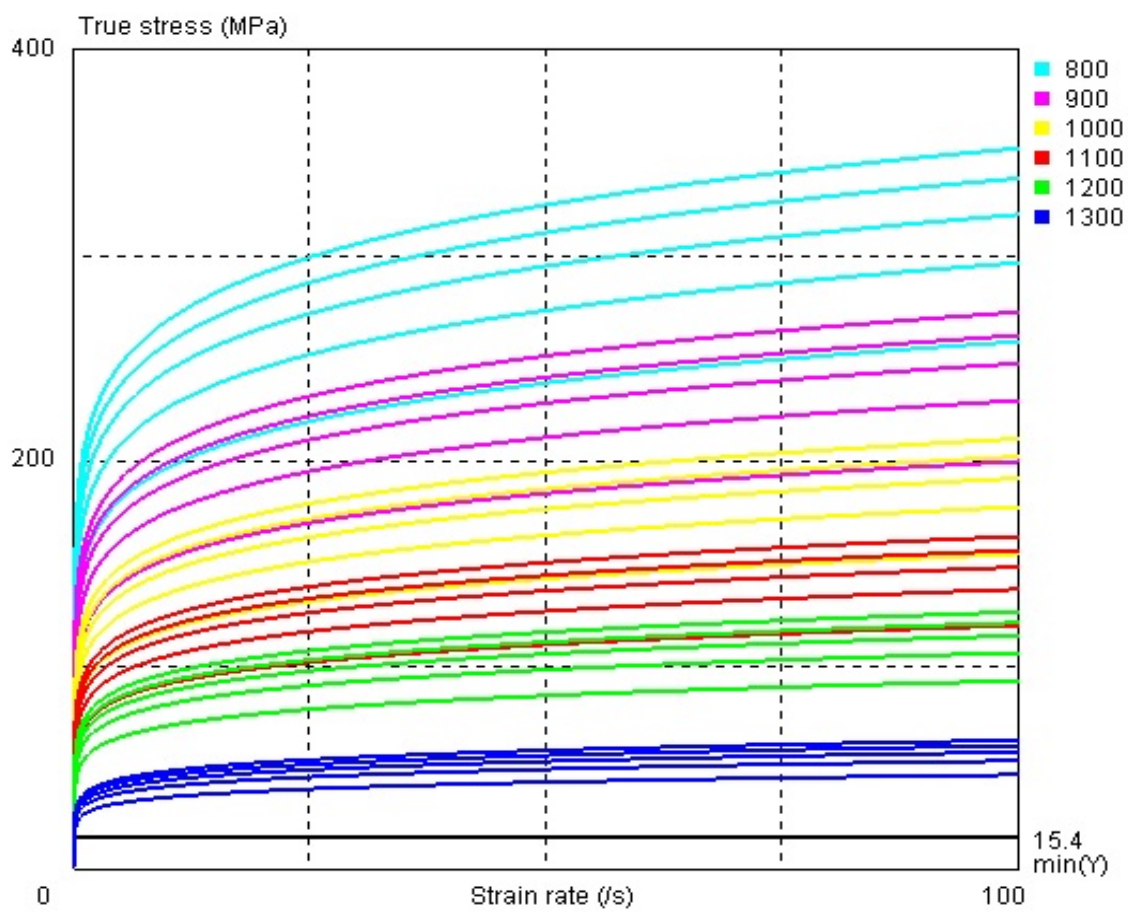

Figure 5: Flow stress of SCM440 alloy steel in the AFDEX library

\subsection{AFDEX Friction Model}

Implementing a friction model in the forging simulation requires assumption on how the behaviour of the friction. There are two ways of how to enter friction condition inside AFDEX. Use the available model in the AFDEX library. For advance user, or if the model need to be customized, the friction can be entered in the manual model. The user have to select the friction model and the related contant parameter. There are two ways to enter the maximum allowable penetration limit. Firstly, using the auto generation feature, AFDEX calculates the proper value. Another feature is touch limit. A minimum gap when the contact between dies and workpiece can be considered occur (Han. et al., 2013).

\subsection{AFDEX Dies Movement and Forming Control}

The forming process can be performed by configuring the movement of the dies. It is a combination of movement between upper and lower dies. In AFDEX, the motion control can be configured as a Force vs. Distance or Force vs. Time. One of the differences between press forging and hammer forging simulation is the time or distance setting. Press forging can be configured by set the Force vs. Time slower and vice versa for the rotary forging. Another configuration setup that governs the dies movement is the machine configuration.

After finishing all the modelling stage, the last required step is the forming control. It is about configuring the computing process. The behaviour of the analysis and how computer perform the computation and iteration will be governed from this setting. To determine how deep the die penetrates the workpiece is by pointing one point at the die's corner and another point at workpiece's corner. AFDEX will measure the distance between those points and set it as the distance of die's movement. 


\section{ORBITAL MOTION ANALYSIS}

Identifying the orbital motion of conical die is important during the design stage. The plot of orbital is generated using the plot3 function available in MATLAB. There are four parameters involve in this orbital motion plot: the Nutation angle $(N)$, the Precession $(P)$, the Spin $(N)$ and the rocking die mechanism as it represented by the cyclic translation movement in $-y$ axis. Figure 6 shows the setup for the orbital motion analysis. The cylindrical geometry at the base is representing the workpiece. The conical shape with the longer cylindrical part is representing the conical upper die and the rocker arm. Location of interest is marked as point Pt1. The following orbital plots as shown in the next figures are based on this point Pt1.

\subsection{Orbital Motion of the Rotary Press Forging}

The first orbital motion of the conical upper die is shown in the Figure 7. For example, the "N5+=-30OC1PC1SC1" can be breakdown into Nutation part "N5+=-300C1" means that the Nutation $(\mathrm{N})$ angle is $5^{\circ}$ with the amplitude $30^{\circ}$. Therefore, the Nutation angle will be varied from $-25^{\circ}$ to $35^{\circ}$ with the frequency one cycle as stated with the code " $\mathrm{Cl}$ ". It is considered a slow nutation mechanism. The next code is "PC1" which is representing the Precession angle. It is a fully cycle from $0^{\circ}$ to $360^{\circ}$. The last code is $\mathrm{SC} 1$ which is representing the Spin angle with a fully one rotation cycle.

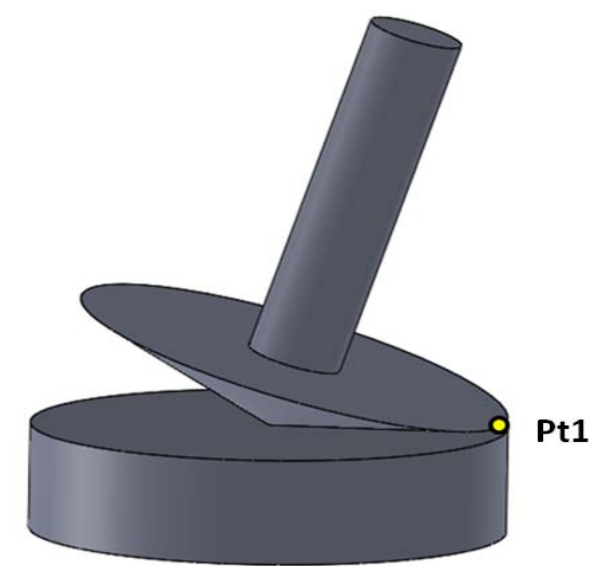

Figure 6: The geometrical setup of orbital motion analysis

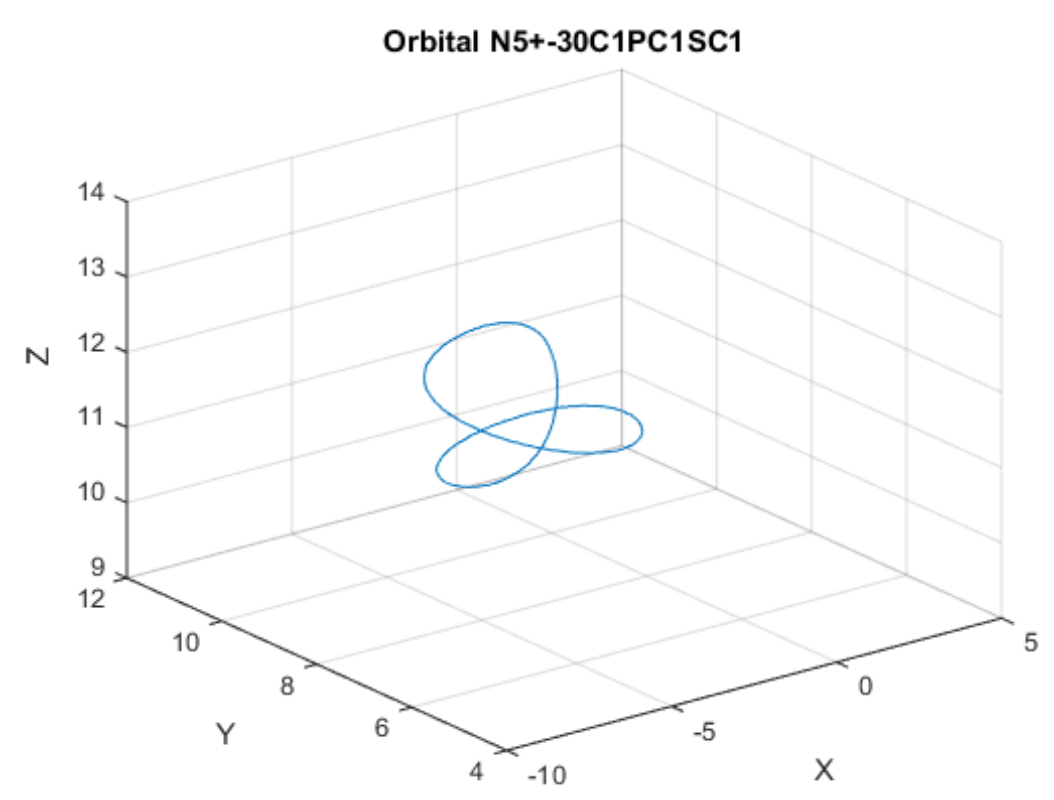

Figure 7: Orbital plot of point Pt1 with $\mathrm{N}$ (Nutation angle) $=50 \pm 300$ with $\mathrm{P}$ (Precession) and S (Spin) are rotated simultaneously 


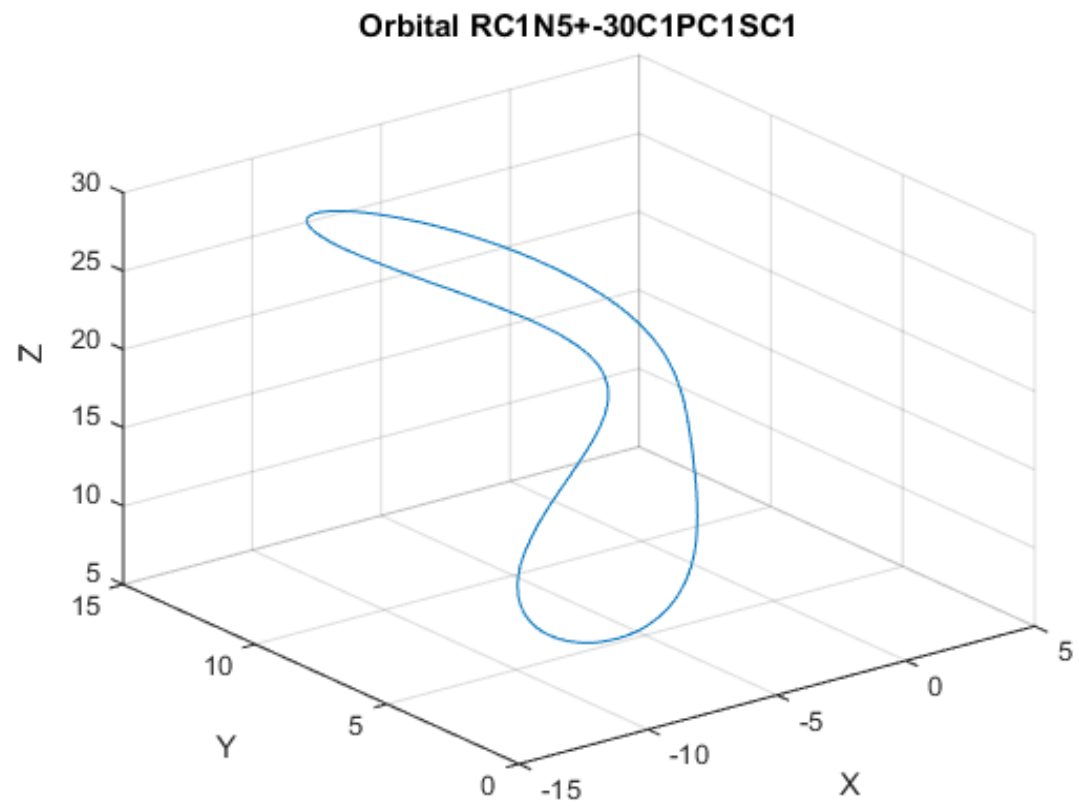

Figure 8: Orbital plot of point Pt1with R (Rocking-Die) at $10 \mathrm{~mm}$ amplitude, $\mathrm{N}$ (Nutation angle) rotates at $5 \mathrm{O} \pm 30 \mathrm{O}$, $\mathrm{P}$ and $\mathrm{S}$ are rotating simultaneously

\subsection{Orbital Motion of the Rotary Hammer Forging}

The difference between rotary press forging and rotary hammer forging can be seen by the additional parameters that vary during the forging process. There is an additional vertical movement along $-y$-axis that represent the rocking-die mechanism. Followings are the result of orbital motion plot with the additional code $\mathrm{R}$ in the first digit of name coding. The additional letter of $\mathrm{R}$ code can be found in the first three digits of the coding name as shown in the first orbital motion of the conical upper die as shown in Figure 8. The label "RC1" means that (1) the orbital motion is belong to the rotary hammer forging and (2) the vertical axis (y) is moving in a periodic manner. Figure 8 shows the orbital motion with the configuration is as follow: Rocking die mechanism with stroke $10 \mathrm{~mm}$, and Nutation angle rotates between $-25^{\circ}-35^{\circ}$ angle while $\mathrm{P}$ and $\mathrm{S}$ are rotating simultaneously. Figure 9 shows the orbital motion with the configuration is as follow: Rocking die mechanism with stroke $10 \mathrm{~mm}$, and Nutation angle rotates between $-25^{\circ}-35^{\circ}$ angle while $\mathrm{P}$ is stationary and $\mathrm{S}$ is rotating simultaneously.

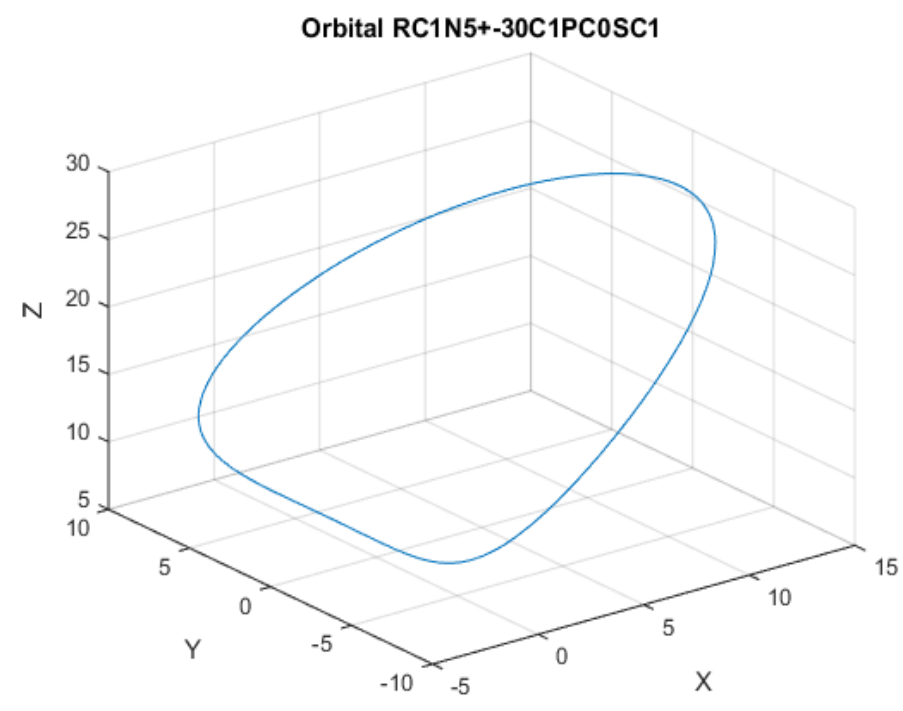

Figure 9: Orbital plot of point Pt1with R (Rocking-Die) at $10 \mathrm{~mm}$ amplitude, $\mathrm{N}$ (Nutation angle) rotates at $5^{\circ} \pm 30^{\circ}$, $S$ rotates and $\mathrm{P}$ is stationary. 


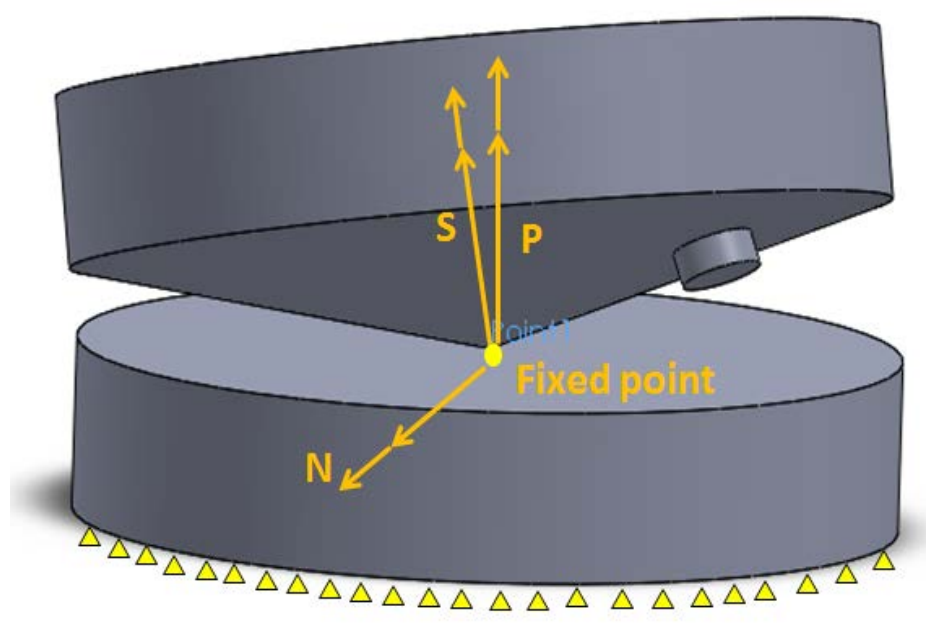

Figure 10: Boundary condition of the rotary hammer forging

\section{ANALYSIS ON INDENTATION MECHANISM}

The definition of the indentation mechanism is the mechanism that shows how the conical upper die penetrate and deform the upper part of the workpiece under particular rotary hammer forging motion. In this chapter, the mechanism as well as the contour of the pressure state was investigated and discussed.

\subsection{CAD Design and Meshing}

The CAD design of upper conical die and the workpiece with small cylinder feature were developed using Solidworks application. The conical angle of the upper conical die is $15^{\circ}$. The small feature is a extruded cylinder with the diameter $5 \mathrm{~mm}$ and $2 \mathrm{~mm}$ depth. The purpose of this small feature is to give indentation to the workpiece. The outer diameter of upper conical die as well as the model of workpiece is $50 \mathrm{~mm}$ length. The thickness of the workpiece is $10 \mathrm{~mm}$. For the workpiece, since it will suffer elastic-plastic deformation, the meshing size becomes concern. Later on, after every step or iteration during analysis, the meshing will be updated. AFDEX was set to read the last result of deformation become the initial element for the next result.

\subsection{Determining the Boundary Condition}

The next stage, which is the determination of the boundary condition, becomes the crucial stage. A set of boundary condition will govern the result and the behaviour of the system. In fact, it is the most difficult stage in the finite element analysis. It is different with the geometry or profile of the product. Nowadays, with many available and sophisticated CAD software, it is easy to follow and model any shape or geometry of a product. No matter how complex or intricate any shape of object, with a higher degree of curve equation, it is not a problem anymore.

Wrongly adjust the boundary condition; the behaviour will be far from the real condition. Figure 10 shows the boundary condition being applied to the rotary hammer forging system. Some assumptions have been made as a reason to decide such the boundary condition. Firstly, the analysis only concern at the upper part of the workpiece. The lower part of the workpiece was considered rigid. Therefore, the fixed boundary condition was applied at the bottom surface of the workpiece.

Three axes labelled with $\mathrm{N}$ for Nutation, $\mathrm{S}$ for spin and $\mathrm{P}$ for Precession were defined. Two arrow pointers showing the vector direction of the rotation. The behaviour of the N, S, P and-y (rocking die mechanism) depends on the configuration of those parameters. This model then was integrating the orbital motion result. The analysis uses the orbital motion of the conical upper die. In order to increase the frequency of indentation, the frequency of Nutation angle have to be quadrupled the initial speed. With the completion of all the modelling stages, the finite element system was ready to be analysed. It can be observed seen that the indentation result showing an exact location with the angle between holes is $90^{\circ}$.

\section{CONCLUSIONS}

From this research, some conclusions can be summarized as follows:

1. Comparing to other conventional forging process, rotary forging has many advance features that can overcome the limitations of their predecessor. The future of the rotary forging process is promising. 
2. The flow stress and deformation of the workpiece in rotary forging is not uniform. The non-homogeneity of both parameters is getting more significant in a more complex shape of workpiece as well as dies. These issues should be considered when designing the workpiece, dies as well as the process.

3. The force required to perform the rotary forging is lower than the conventional forging. Therefore, the process will reduce the energy consumption.

4. Since the contact region between workpiece and upper die is smaller than the contact area of the conventional forging, the lifetime of the dies are longer for rotational forging.

5. The relation between rotary forging parameters such as Nutation, Spin and Precession govern the indentation mechanism on the rotary forging have been comprehensively investigated by modelling a three dimensional elastic-dynamic plasticity under AFDEX environment.

6. From the simulation, the indentation pattern behaviour on the process of the rotary forging can be revealed. It will produce a guideline during design, assembly and installation stage and set of knowledge about how the flow of material performs during forging process.

7. The inclination angle and the angular speed of the upper die play a significant role on the flow of material and deformation homogeneity in the workpiece. Maximum forging force in axial direction can be achieved by the smaller inclination angle of the upper die.

8. Rising the angular rotating speed of lower die and reducing the angle of inclination improve the flow of the material in the workpiece.

\section{RECOMMENDATION}

Since the prospect of the development of rotary hammer forging is still wide open. Some suggestions and recommendations for the future works are as follows:

1. The possibility to develop a specific and tailor made CAD and CAE software to automate the work of generating the pattern so more user with less technical background can utilize the tools

2. Development of a new machine with new kinematic mechanism that can allow utilizing all rotary forging parameters. The new system will allow to generate any kind of pattern by adjusting, activating or deactivating some of the rotary forging parameters.

\section{ACKNOWLEDGEMENT}

The authors would like to appreciate very much the experimental and analytical support from Department of Manufacturing and Materials Engineering in doing this research.

\section{REFERENCES}

1. Han X. \& Hua L. (2009). Comparison between cold rotary forging and conventional forging. Journal of Mechanical Science and Technology, 23, 2668-2678.

2. Han, X. H. \& Hua, L. (2013). 3D FE Modelling of Contact Pressure Response in Cold Rotary Forging. Tribology International, 57(1), 115-123.

3. Han, X. H., Hua, L., Zhuang, W. H. \& Zhang, X. C. (2014). Process Design and Control in Cold Rotary Forging of Non-Rotary Gear Parts. Journal of Materials Processing Technology, 214(11), 2402-2416.

4. Yongning, M. M. S. (2009). Forging Process Design for Risk Reduction. PhD Theses, The Ohio State University.

5. Biglari, F. R., O'Dowd, N. P. \& Fenner, R. T. (1998). Optimum design of forging dies using fuzzy logic in conjunction with the backward deformation method. International Journal of Machine Tools and Manufacture, 38(8), 981-1000.

6. Malhotra, R., Cao, J., \& Ren, F. (2011). Improvement of Geometric Accuracy in Incremental Forming by Using a Squeezing Toolpath Strategy with Two Forming Tools. ASME Journal of Manufacturing Science and Engineering, 133(6), 061019.

7. Zhang, Y. Q., Shan, D. B., Xu, W. C. \& Lv, Y. (2010). Study on Spinning Process of a Thin-Walled Aluminum Alloy Vessel Head with Small Ratio of Thickness to Diameter. ASME Journal of Manufacturing Science and Engineering, 132(1), 014504.

8. Merklein, M., Plettke, R. \& Opel, S. (2012). Orbital forming of tailored blanks from sheet metal. CIRP Annals: Manufacturing Technology, 61, 263-266.

9. Lin H.-R. \& Wang Y.-H. (2005). FEM Simulation for Swing Die method. Journal of Jiangxi Nonferrous Metals. (9), 40-42.

10. Morakabati, M., Aboutalebi, M., Kheirandish, Sh., Karimi Taheri, A., and Abbasi, S. M. (2011). High temperature deformation and processing map of a NiTi intermetallic alloy. Intermetallics 19, 1399-1404. 